\title{
Uniaxial Strength and Deformation Properties of Machine-Made Snow
}

\author{
Nina Lintzén ${ }^{1}$ and Tommy Edeskär ${ }^{2}$
}

\begin{abstract}
Snow as a construction material has been used for centuries, with igloos among the first examples. Each winter, snow and ice villages, buildings, and artwork are built in many places around the world. Machine-made snow manufactured by snow guns is commonly used for constructions made of snow. However, only a few basic studies on machine-made snow have been published. Knowledge based on experience and studies on natural snow constitute the basis for constructions made using snow and ice. Through material tests on machine-made snow used for construction, data on important physical and mechanical properties have been established that aim to improve and optimize safe constructions made from snow. Strength tests have been performed using two different qualities of machine-made snow. Specimens used for testing were cut out from one block of snow that had a coarse-grained structure with clusters of ice in the snow and from one block of snow with a fine-grained and homogeneous structure. The density for each tested snow sample was measured and strength tests were performed at different deformation rates to investigate the relationship between mechanical properties and deformation rate or strain rate. The load response curves achieved from the strength tests were used to evaluate compressive strength, Young's modulus, and the residual modulus. The results show that compressive strength increases with increasing density. Increasing compressive strength with an increasing strain rate was also observed for fine-grained snow quality specimens, whereas no similar tendency was observed for coarse-grained snow. The residual modulus increased with an increasing strain rate up to a certain critical value for the fine-grained machine-made snow specimens. Regression analysis was used to investigate whether any dependence was observed between the calculated mechanical properties; no further relationship between the mechanical and the physical properties was noticed. DOI: 10.1061/ (ASCE)CR.1943-5495.0000090. (C) 2014 American Society of Civil Engineers.
\end{abstract}

\footnotetext{
${ }^{1} \mathrm{Ph} . \mathrm{D}$. Student, Dept. of Civil, Environmental and Natural Resources Engineering, Luleå Univ. of Technology, 97187 Luleå, Sweden (corresponding author). E-mail: nina.lintzen@ ltu.se

${ }^{2}$ Assistant Professor, Dept. of Civil, Environmental and Natural Resources Engineering, Luleå Univ. of Technology, 97187 Luleå, Sweden. E-mail: tommy.edeskar@ltu.se

Note. This manuscript was submitted on September 10, 2013; approved on October 10, 2014; published online on November 18, 2014. Discussion period open until April 18, 2015; separate discussions must be submitted for individual papers. This paper is part of the Journal of Cold Regions Engineering, (C) ASCE, ISSN 0887-381X/04014020(17)/\$25.00. 


\section{Introduction}

During the past few decades, the recreational-based snow industry has grown. In addition to use in sports activities, snow and ice have been used in buildings and construction. Each year, villages, hotels, and artwork made with snow and ice are built in several places around the world. The construction is generally done using knowledge based on experience. Current knowledge on the mechanical properties of snow is based on research on natural snow from the mid-twentieth-century (e.g., Bader 1962; Mellor 1974; Kinosita 1967). Machine-made snow—snow produced by snow guns-is commonly used to construct snow buildings. In many respects, the properties of machine-made snow are different from those of natural snow. Natural snow initially consists of crystals with infinitely many different structures and shapes, whereas machine-made snow consists of frozen water droplets, or round grains. The small round grains of machine-made snow result in a more closely packed structure and a higher density compared with fresh natural snow. The shape of these grains also makes machine-made snow more stable and more durable in warm temperatures, precipitation, and wind (ICEHOTEL 2011).

Only two minor scientific studies have been conducted on machine-made snow as a material used in construction. These studies addressed field and laboratory measurements at ICEHOTEL, Jukkasjärvi, Sweden, which were retrieved during the 2000-2001 season (Vikström and Bernspång 2002) and the 2010 season (Lintzén and Edeskär 2012). Unconfined compression tests, confined and unconfined creep tests, and deformation studies were performed on machine-made snow and snow structures from ICEHOTEL (2011) in Jukkasjärvi, Sweden. The obtained results imply that machine-made snow has different mechanical properties compared with natural snow of the same density. Further research is necessary to establish material data for machine-made snow.

In this study, unconfined compression tests on machine-made snow were performed to investigate basic material properties and to relate compression test data to outer parameters. Previous studies showed that natural snow under compression behaves differently depending on the deformation rate (Kinosita 1958, 1967). These studies also showed that snow is a viscoelastic material for which slow deformation results in a continuous deformation process and an elastic-plastic behavior. Fast deformation results in a discontinuous deformation process or brittle failure. The critical deformation rate between plasticity and brittleness is important to the load response of snow and-in addition to the speed of deformationdepends on the density, temperature, and structure of the snow tested.

Unconfined compression tests were performed at different deformation rates but constant temperature to get an idea of how the deformation rate affects the mechanical behavior. Two different types of machine-made snow were used for the strength tests, one with a coarse-grained structure and one with a fine-grained structure. The air-water mixture in the snow gun, the pressure, and the outer climate conditions are important to the quality of the machine-made snow being produced (Chen and Kevkorian 1971). In this study, coarse-grained snow was created with a relatively higher amount of water, creating snow of high density and clusters of ice in the snow. Fine-grained snow was produced using relatively less water that, in combination with other parameters being optimized, resulted in a homogeneous and finegrained structure of machine-made snow. 
The results show that mechanical properties depend on the structure of the snow. Coarse-grained snow showed scattered results, whereas fine-grained snow provided consistent values for tests performed in controlled conditions. Compressive strength is similar to values obtained in previous studies on machine-made snow (Lintzén and Edeskär 2012). Young's modulus values are difficult to compare with values obtained in other tests because the methods used to evaluate this property generally vary, which seems to have a significant effect on the results.

\section{Method}

\section{Material}

The machine-made snow used in this investigation was produced with snow guns and was then mixed twice with a snow blower before being cast in a rectangular mold and allowed to freeze to form a block of snow. In this study, specimens from two different blocks of machine-made snow were used for the strength tests. One of the blocks had a coarse-grained structure with clusters of ice in the snow. This block was produced in November 2011 and stored in a freezing room at approximately $-10^{\circ} \mathrm{C}$ for 1 year before test specimens were cut out and compression tests were performed. This machine-made snow is denoted as old snow. The other block of snow had a homogeneous and fine-grained structure. This block was produced in March 2013 and specimens were cut out and tested within 2 weeks of production. This type of snow is denoted as new snow. Both blocks of snow were stored under diffusion-proof plastic covers in freezing rooms to protect them from sublimation and to retain the structure of the snow. Backlight projection and image analysis were used to study the structure of the snow, which are shown in Figs. 4 and 5.

\section{Test Procedure}

\section{Sample Preparation}

Cylindrical test specimens were drilled out from the blocks of snow and then were cut to the desired length using a miter box to ensure that the end surfaces were flat and that all specimens were exactly the same length. The initial size of the test specimens used for the strength tests had a diameter of $65 \mathrm{~mm}$ and a length of $150 \mathrm{~mm}$. A linear pattern was drawn on the specimens' surface to study the longitudinal deformation behavior (Fig. 1). Each individual sample was weighed to determine its density.

\section{Strength Tests}

The cylindrical specimens were tested during uniaxial compression at different constant deformation rates. Paper sheets were put between the test specimen and the load plates at the ends to prevent the test specimen from freezing into the load plate surfaces, which may cause undesired end effects with these specimens. During each test, the resisting force was recorded with a load cell and the longitudinal compression was measured as the displacement of the load platens using strain gauges with 


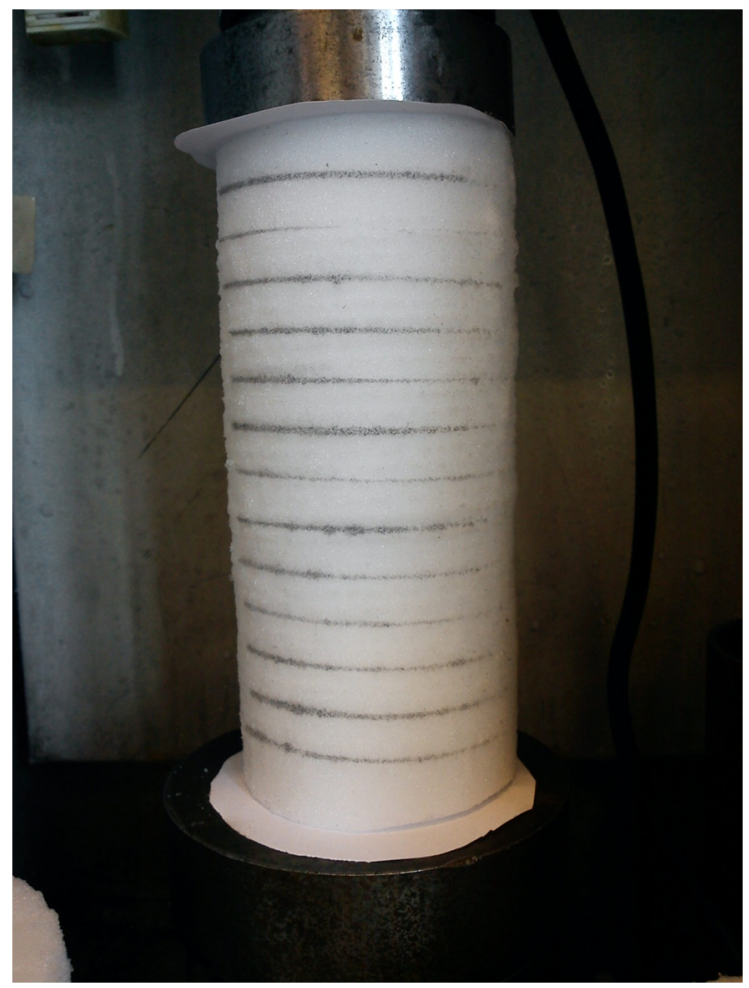

Fig. 1. Specimen used for compressive test

an accuracy of $\pm 0.001 \mathrm{~mm}$. Strength tests were carried out at deformation rates from 0.5 up to $40 \mathrm{~mm} / \mathrm{min}$. The temperature during the performed tests was approximately $-10^{\circ} \mathrm{C}$. Between three and five tests were performed at each deformation rate. The Appendix shows the experimental layout with the number of test samples at each deformation rate for the two different types of machine-made snow tested.

\section{Evaluation}

The compressive strength, Young's modulus, and the residual modulus were evaluated using the results from the uniaxial strength tests.

Fig. 2 shows a typical force versus time curve from a compressive test using new machine-made snow. The compressive strength of each snow sample was calculated by dividing the registered peak load during the loading procedure at a constant rate of strain by the initial cross-sectional area of the test body, according to Eq. (1)

$$
\sigma=\frac{F_{\max }}{A}
$$




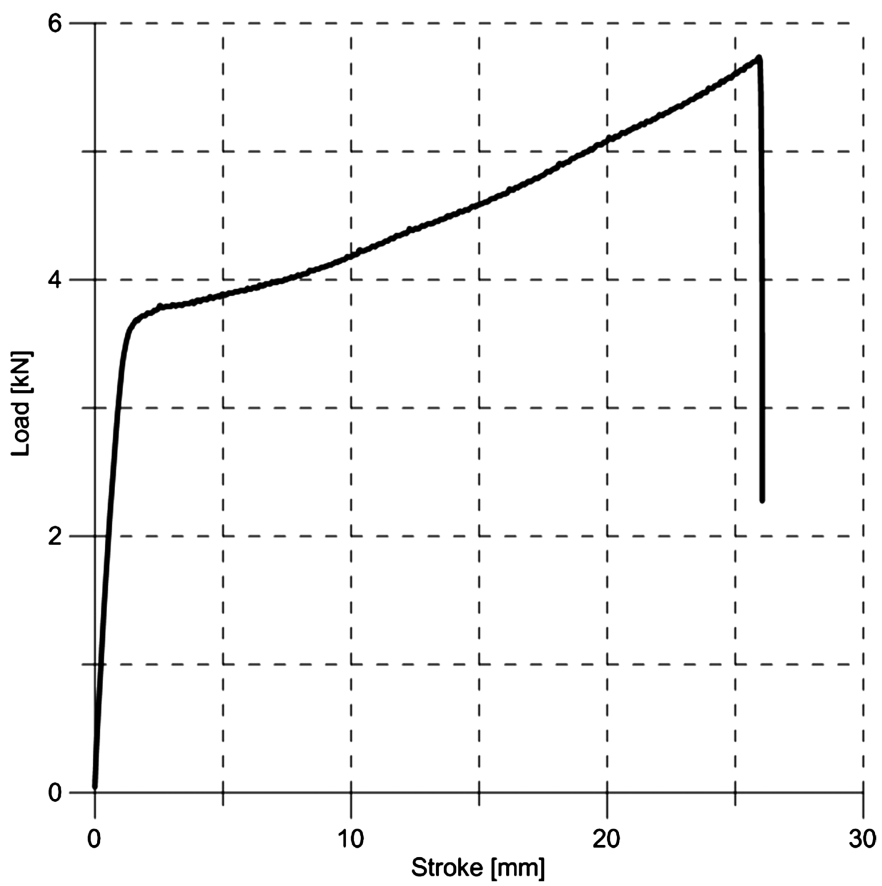

Fig. 2. Typical force versus displacement curve from a uniaxial compressive test with new machine-made snow for which no brittle failure occurred during an early stage of the load process; the deformation rate was $12.5 \mathrm{~mm} / \mathrm{min}$

where $\sigma=$ compressive strength; $F_{\max }=$ maximum registered force; and $A=$ initial cross-sectional area. Young's modulus, $E_{\tan }$, was evaluated as the tangent modulus to the stress-strain curve during the initial phase of the load test, in other words, before the peak point or ultimate load was reached, as shown in Fig. 3. The difference in stress was divided by the difference in strain, according to Eq. (2)

$$
E_{\tan }=\frac{\Delta \sigma}{\Delta \varepsilon}
$$

In this study, the stage after the load peak is reached is defined as the postload process and corresponds to the residual strength. As is shown in Fig. 3, an almost linear relationship between $\Delta \sigma$ and $\Delta \varepsilon$ is observed unless the test specimen cracks or fails. The residual value, $E_{\text {res }}$, is evaluated as the quotient between $\Delta \sigma$ and $\Delta \varepsilon$ according to Eq. (3)

$$
E_{\mathrm{res}}=\frac{\Delta \sigma}{\Delta \varepsilon}
$$




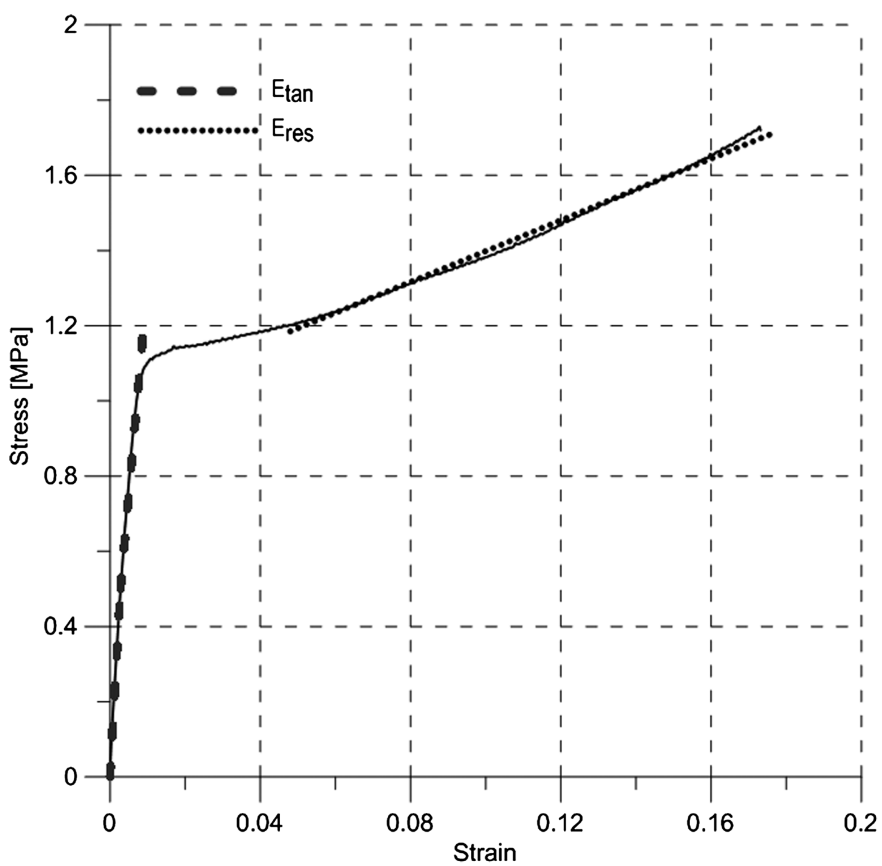

Fig. 3. Typical stress-strain curve from a load test for which no brittle failure occurred during an early stage of the load process; the deformation rate was $12.5 \mathrm{~mm} / \mathrm{min}$

\section{Results}

Fig. 4 shows the structure of the old snow and Fig. 5 shows the structure of the new snow. The individual grains for the old machine-made snow were observed to be coarse, were a broad range of sizes, and were unevenly distributed throughout the cross section. Some ice clusters also existed in the structure. The individual grains from the sample of new machine-made snow were fine grained, equal in size, and evenly distributed without any clusters of ice.

Fig. 6 shows the variance in the density for the two different snow qualities. The densities for the old snow specimens varied between 550 and $710 \mathrm{~kg} / \mathrm{m}^{3}$. The densities for the new snow specimens were more analogous and varied from 510 to $560 \mathrm{~kg} / \mathrm{m}^{3}$. In general, the new snow had lower density that the old snow. The density was lower for the specimens of new machine-made snow, and the density variance was higher for the old machine-made snow.

Fig. 7 shows the compressive strength versus the density for old and new machinemade snow samples. The tests were performed at deformation rates between 5 and $40 \mathrm{~mm} / \mathrm{min}$. The results showed the tendency for compressive strength to increase as density increased for both the new and old machine-made snow samples. However, the mean value of the compressive strength was higher for the new snow 


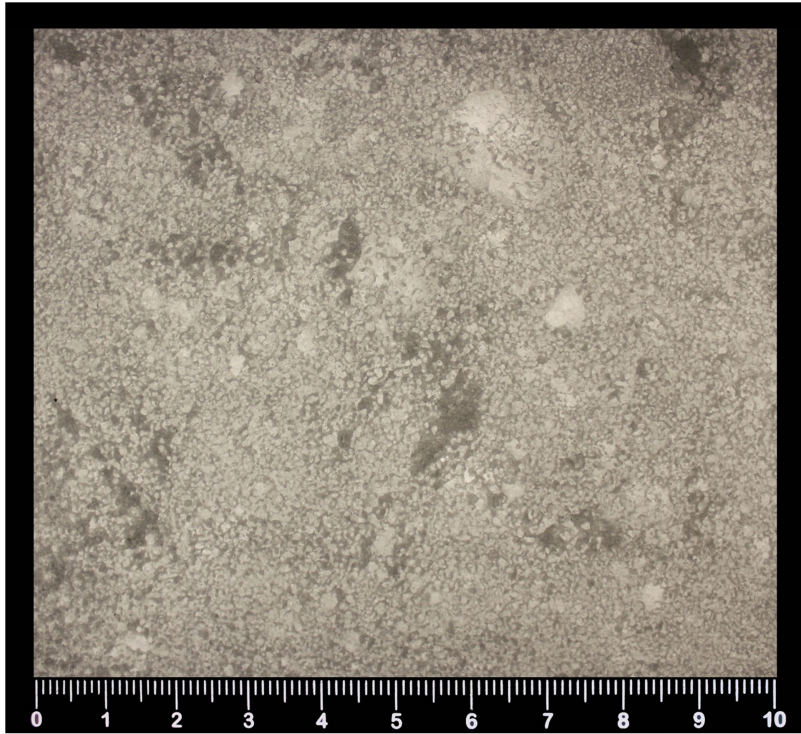

Fig. 4. Structure of the old snow

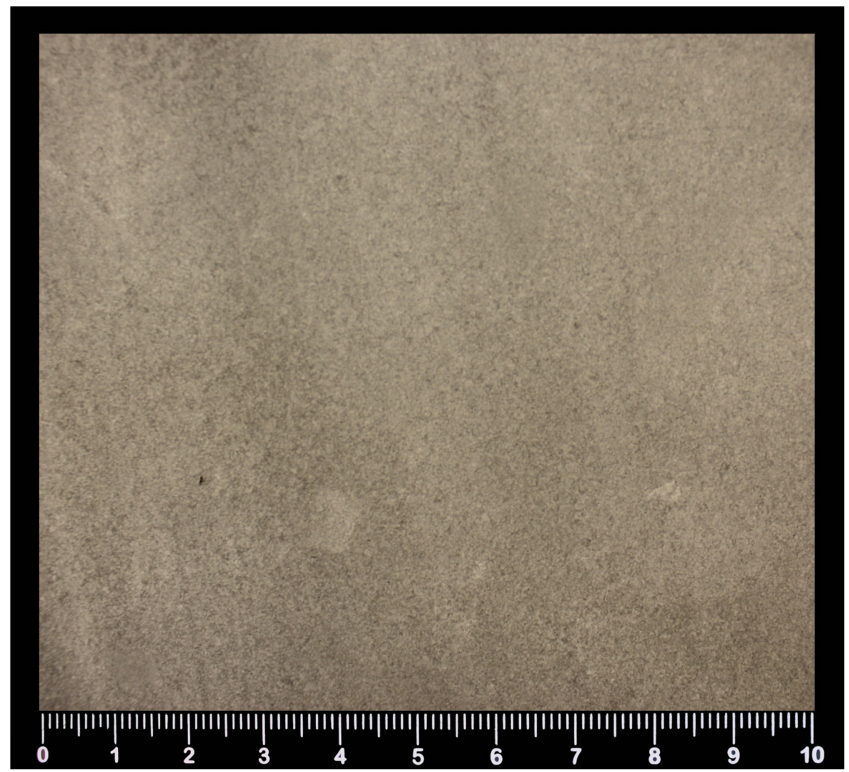

Fig. 5. Structure of the new snow
(C) ASCE
04014020-7
J. Cold Reg. Eng.

J. Cold Reg. Eng. 


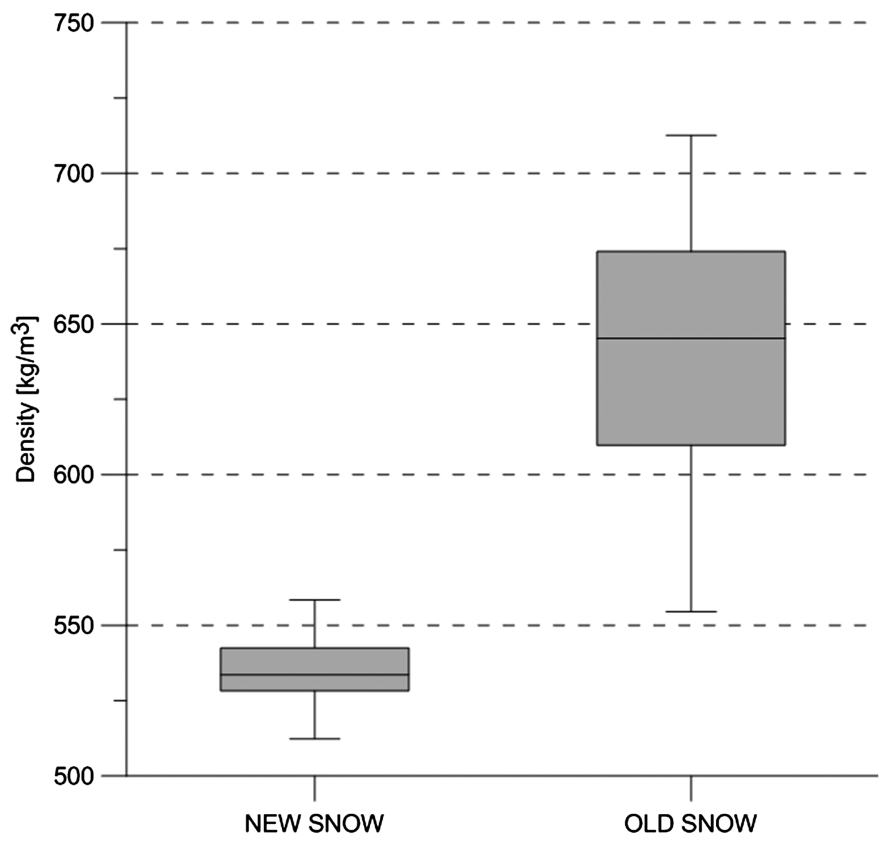

Fig. 6. Density of the new and old snow specimens

than for the old snow, although the density of the new snow was lower than the density for the old snow.

Young's modulus is defined as the tangent modulus up to the registered peak stress. Fig. 8 shows Young's modulus versus the density of the old and new machinemade snow samples. The Young's modulus values were much more scattered for the old snow samples than for the new snow samples; however, the results for both snow types showed no clear tendency for dependence between these two properties.

Fig. 9, which indicates the compressive strength versus the strain rate, shows that the compressive strength was more scattered for the old snow than for the new snow. The compressive strength of new machine-made snow increased as the strain rate increased. Given the scattered data values, no similar clear dependency was observed for old machine-made snow.

Fig. 10 compares Young's modulus versus the strain rate for the old and new artificial snow samples. The average value of Young's modulus, $E_{\tan }$, was $115 \mathrm{MPa}$ for the tested specimens of old machine-made snow and $162 \mathrm{MPa}$ for the tested specimens of new machine-made snow. The results were more scattered for the old machine-made snow.

Fig. 11 shows the residual modulus, $E_{\text {res }}$, versus the strain rate for the tests performed on new machine-made snow. The values increased as the strain rate increased and varied between approximately 3 and $9 \mathrm{MPa}$.

Most of the tests on the old machine-made snow specimen were either interrupted after the peak point was reached or after the samples cracked, yielding a 


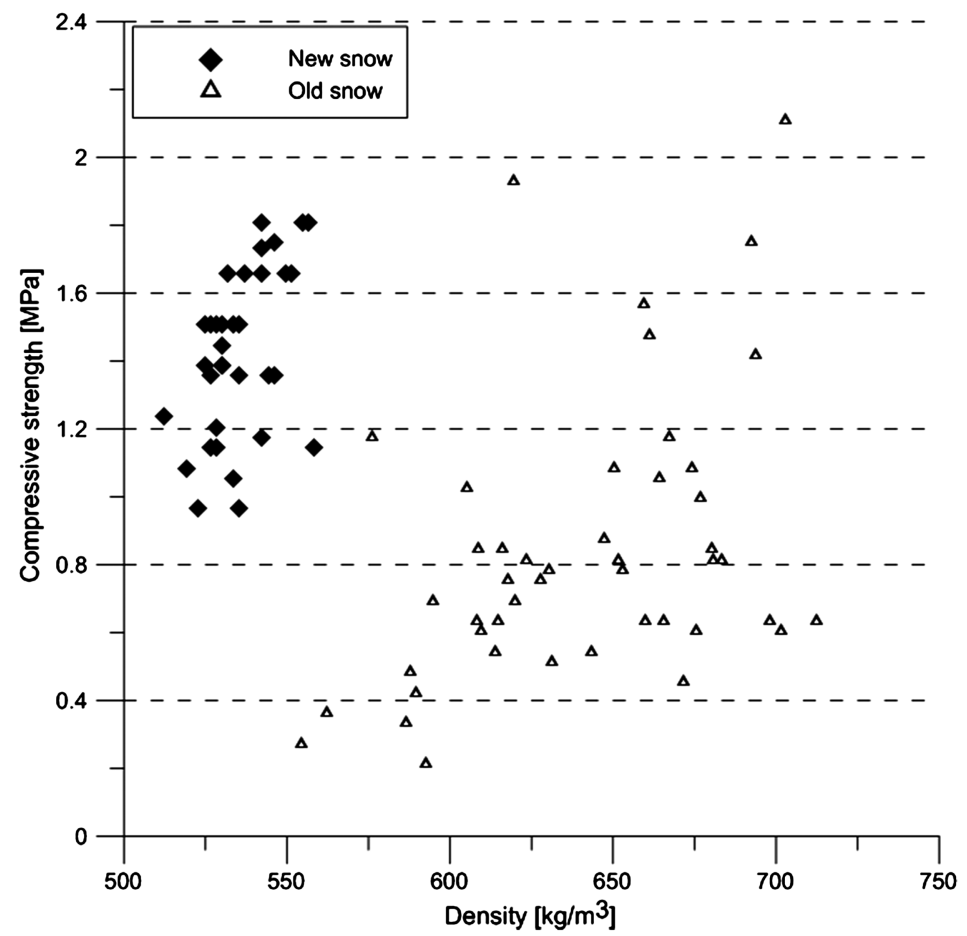

Fig. 7. Compressive strength versus density of all specimens and deformation rates

saw-tooth curve instead of a linearly increasing line, as shown in Fig. 2. For a few tests in which calculating the residual modulus using old machine-made snow was possible, the values varied between 3 and $7 \mathrm{MPa}$. In other words, values in the same range were observed for the new machine-made snow.

\section{Discussion}

The different qualities of the two machine-made snow blocks were the result of both different snow production conditions and aging through sintering of the snowincreased growth of individual ice particles in the matrix. As Fig. 4 shows, the old snow was hard and brittle, with clusters of ice and cavities in the snow block. The inhomogeneous snow made specimen preparation difficult. Some specimens cracked during sample preparation and were not used for testing. The new machinemade snow had a homogeneous and fine-grained structure and did not crack during sample preparation.

As Figs. 4 and 5 show, grain size is larger for the old machine-made snow. This characteristic agrees with previous studies that showed that aging results in increased and varying distribution of grain size (Yong and Fukue 1977). Changes in the internal structure influence the mechanical properties of the snow. 


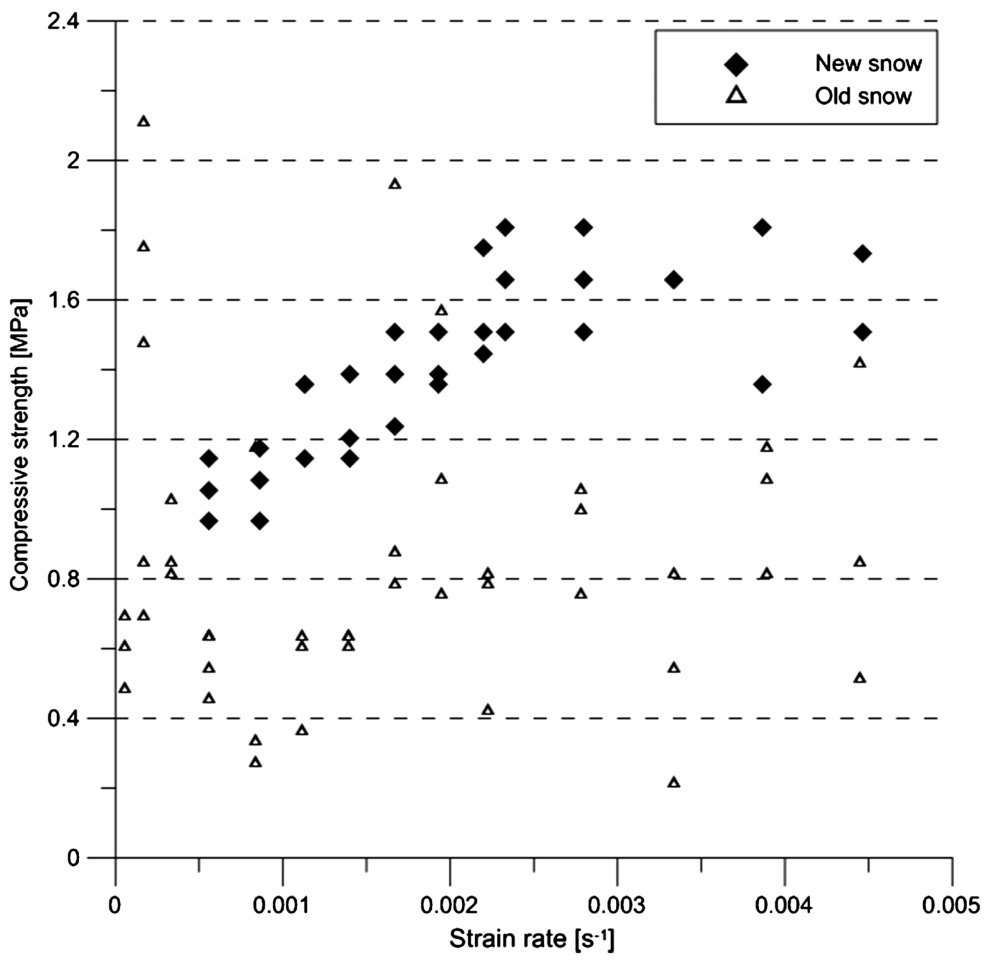

Fig. 8. Young's modulus versus density of all specimens at all deformation rates

The network connections and bonding between ice grains are important for both mechanical properties and the critical deformation rate during compression. This compression separates the elastoplastic behavior observed at low deformation rates that occurs from the brittle failure at higher deformation rates (e.g., Gold 1956; Wakahama 1968; Kinosita 1958, 1967). Wakahama (1968) observed that compression of snow results in several different processes that occur in the ice grains that compose the snow, such as slips at grain boundaries, separation or fracture of ice grains, and migration of grain boundaries. For future studies on machine-made snow, further investigation of grain size and grain size distribution and observation of the structure and deformation behavior at a microscopic level would be interesting to gain additional knowledge on the parameters of importance for the mechanical behavior.

High density variance existed for the old snow test specimens, whereas the density variances for the new snow test specimens were lower. The inhomogeneous structure of the old snow, through which some specimens had high ice content in the snow, resulted in certain specimens with high density and others with less ice having a lower density. Previous studies on machine-made snow from ICEHOTEL showed that the compressive strength increased as density increased 


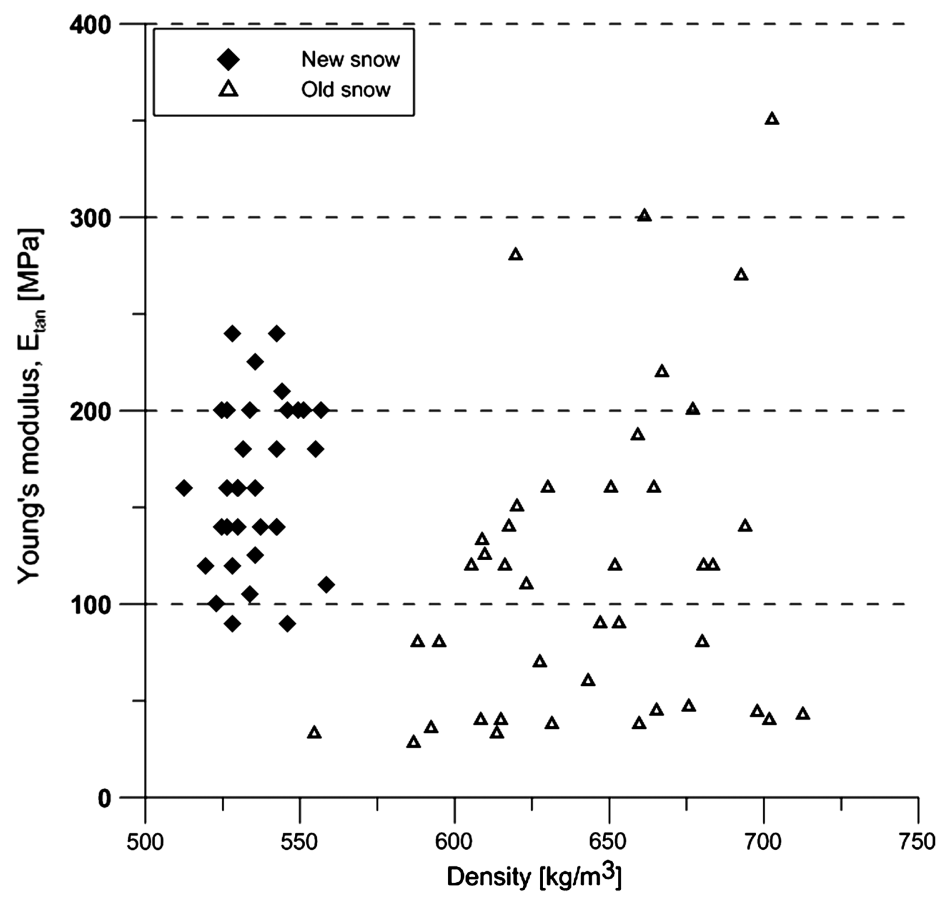

Fig. 9. Compressive strength versus strain rate of all specimens at all deformation rates

(Lintzén and Edeskär 2012). The same tendency was observed from the tests performed in this study; however, snow samples with a high density attributable to high ice content were viewed as not always having higher compressive strength because the ice clusters may also act as initiation points for crack propagation. Density is a common parameter to use as a variable to which mechanical properties are related; however, results from numerous experiments concluded that the response of snow to different loading conditions is better determined by the structure of the snow and the bonding between snow grains rather than its density (e.g., Shapiro et al. 1977; Kinosita 1967; Yong and Fukue 1977). This finding supports the conclusion that investigating and classifying the snow structure on a microscopic scale is of interest for future studies on machine-made snow to correlate grain sizes, grain size distributions, and such parameters to strength and other mechanical properties.

During the compression tests, the initial deformation of the samples was noticed as being uniform along the length axis of the specimen; in other words, the entire specimen was evenly compressed to a shorter and wider shape but still maintained a straight cylindrical form (Fig. 12). The same behavior-a uniform contraction along its entire length-was observed in tests by Kinosita (1967), who concluded that plastic contraction led to hardening of the snow structure as a result of restructuring of ice grains and bonds between grains. 


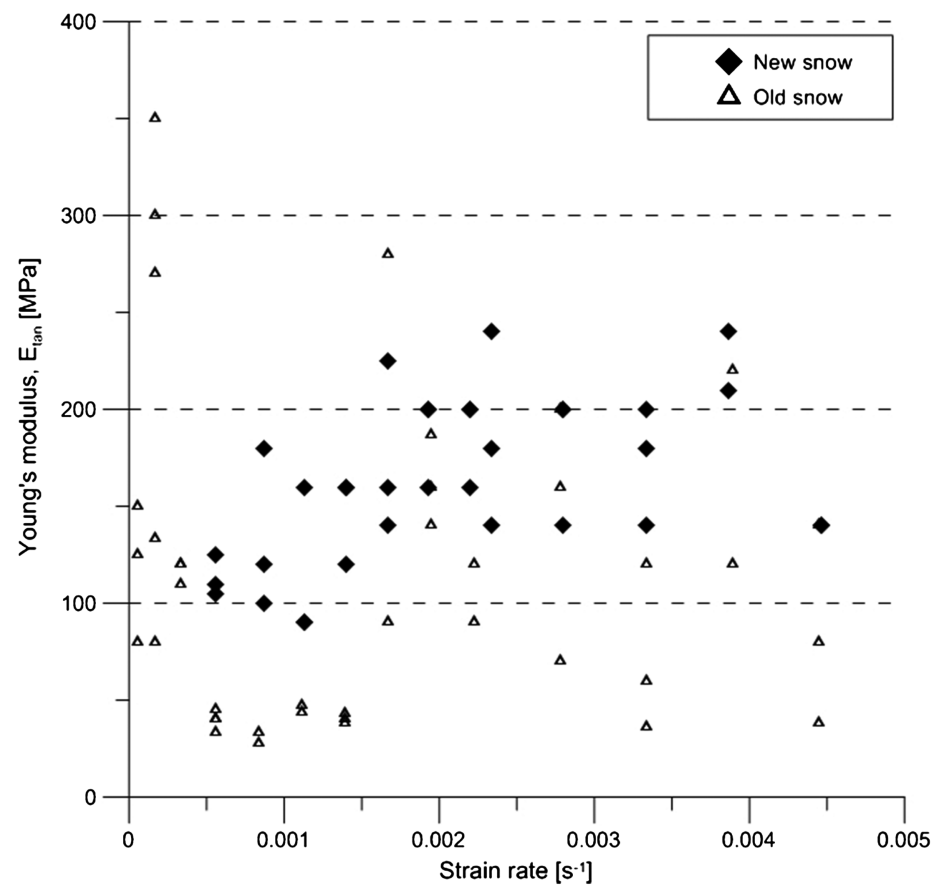

Fig. 10. Young's modulus versus strain rate for all specimens and all deformation rates

The resistive force, which was recorded and used to evaluate the compressive strength and Young's modulus, was initially linear and rapidly increased, as seen in Fig. 2. The interpretation of this initial stage is that a hardening of the structure occurred. If a crack forms during the compression of a specimen without completely breaking, the recorded resistive force may suddenly drop as the crack arises. If the compression is allowed to continue, the resistive force again increases and the slope of the line is approximately the same as before the crack was formed. After reaching the peak value, the resistive force either flattened out or slowly increased unless the test sample cracked or failed, which occurred at high deformation rates. The fractures in the samples were different. Most common was that small cracks occurred before the entire specimen collapsed; however, sometimes a sudden crack occurred throughout the entire specimen, as shown in Fig. 13.

A comparison of the numerical results of the unconfined compressive strength to the results achieved by the strength tests on snow samples taken out from the walls of ICEHOTEL in 2010 shows that the results are in the same range (Lintzén and Edeskär 2012). The compressive strength achieved by Vikström and Bernspång (2002) on samples of machine-made snow at a deformation rate of $1.5 \mathrm{~mm} / \mathrm{min}$ is lower than the compressive strength of the old machine-made snow achieved in this study at the same test temperature and deformation rate. In this study, the new machine-made snow is not tested at this deformation rate. The compressive strength 


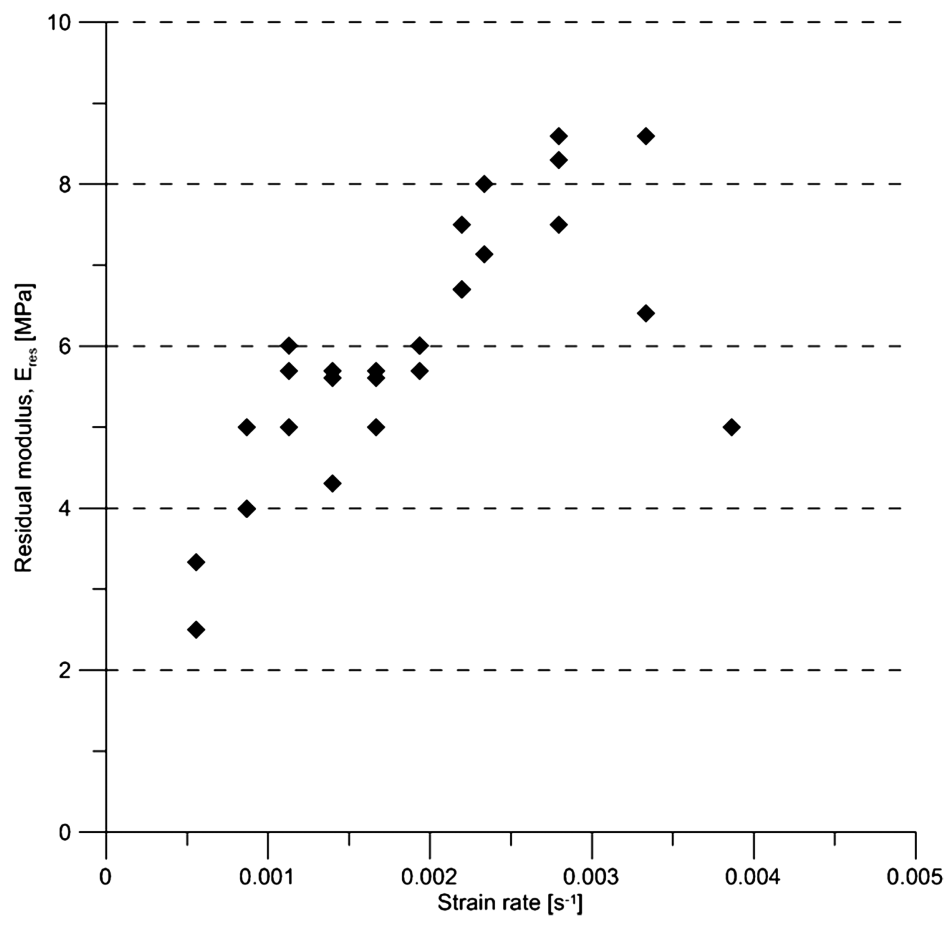

Fig. 11. Residual modulus versus strain rate for all specimens at all deformation rates

is in the same range as the values for natural compact snow with a similar density that was deposited in Hokkaido, Japan, and tested at uniaxial compression at $-13^{\circ} \mathrm{C}$ (Kinosita 1967). Kinosita found that, generally, the compressive strength increases as the density increases. However, this study found that the mean value of the compressive strength for the new machine-made snow was higher than for the old machine-made snow, although the density was generally lower for the new machine-made snow. The densities for all tested samples in this study are higher than for natural snow. This result indicates that the relationship between compressive strength and density might be different for high-density snow than for snow with lower density, a situation that requires further investigation.

The relationship between compressive strength and strain rate indicates an increase in compressive strength as the strain rate increases up to certain critical value. Kinosita (1967) showed that a critical deformation rate exists for natural snow at which the behavior changes from plastic deformation to brittle failure. This breakpoint between plasticity and brittleness is observed in strength tests with new machine-made snow, whereas the scattered data and irregular deformation behavior for the strength tests using old machine-made snow do not allow for any similar observation of a specific critical break point in this study. The critical strain rate for new machine-made snow was noticed to be approximately $0.003 \mathrm{~s}^{-1}$. The corresponding deformation rate was approximately $25-30 \mathrm{~mm} / \mathrm{min}$. Because many of 


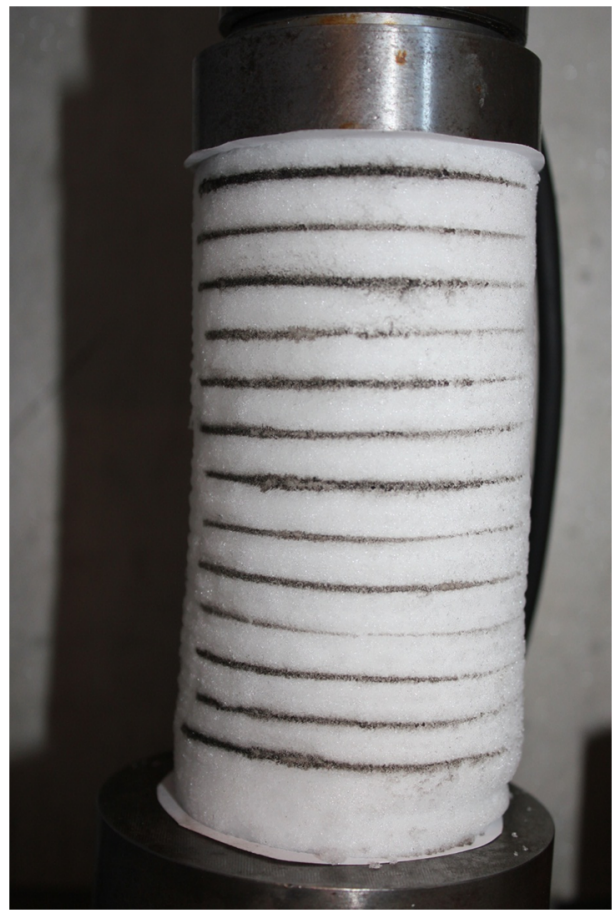

Fig. 12. Test specimen evenly compressed to a shorter and wider shape but still with a straight cylindrical form

the old machine-made snow specimens were brittle, quite a few of them resisted deformation rates higher than $15 \mathrm{~mm} / \mathrm{min}$; however, the results were also scattered at lower deformation rates.

Kinosita (1967) presented an expression that took into account the temperature and density and for which the critical deformation rate was suggested to be approximately estimated as

$$
v_{c}=0.4 T+20 \rho+3
$$

where $v_{c}, T$, and $\rho$ should be given in units of millimeters per minute, degrees Celsius, and grams per cubic centimeter, respectively. Eq. (4) applied to the machine-made snow and temperature conditions in this study predicts critical deformation rates of $9-13 \mathrm{~mm} / \mathrm{min}$. These estimated critical deformation rates are lower than the observed rates in this study. Kinosita's study was based on strength tests using natural snow with, in general, much lower densities than the machinemade snow used in this study, which may provide a reason for the deviating results.

Linear regression analysis was used to approximately quantify whether relations existed between Young's modulus and the resistive modulus rate; however, 


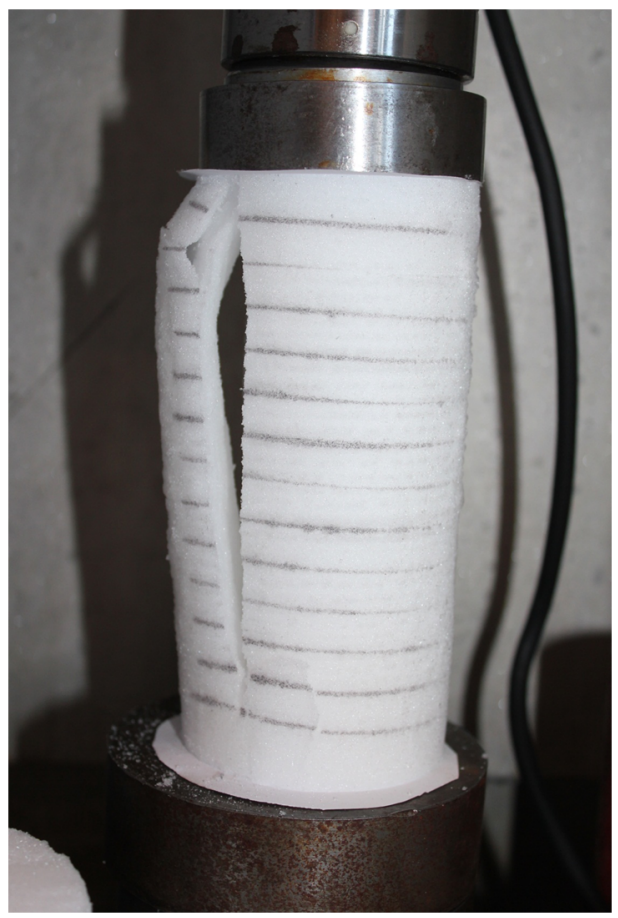

Fig. 13. Specimen that cracked during an early stage of the deformation process during loading at a high deformation rate

no tendency for dependence was observed. Dependence of the moduli toward strain rate was also not observed.

The achieved values of Young's modulus, $E_{\mathrm{tan}}$, were scattered between approximately 50 and $350 \mathrm{MPa}$ for the old machine-made snow samples, and the values were between 100 and $250 \mathrm{MPa}$ for the new machine-made snow samples. Regarding the results of Young's modulus shown in Fig. 9, the significant point is that the values were evaluated from strength tests performed at different deformation rates.

In this study, the results of Young's modulus are in the same range as the values from Mellor (1974) in which tests of uniaxial compression and tension at test temperatures between -12 and $-25^{\circ} \mathrm{C}$ and strain rates between $8 \times 10^{6}$ and $4 \times$ $10^{4} \mathrm{~s}^{-1}$ were used to calculate Young's modulus. However, those tests were performed on natural snow with a density between 150 and $350 \mathrm{~kg} / \mathrm{m}^{3}$. The values of Young's modulus achieved by Bader (1962) were much higher at 1,000 MPa; however, those tests were based on the resonance vibration of bars. Vikström and Bernspång (2002) used tests on machine-made snow beams to estimate Young's modulus value at an average of $335 \mathrm{MPa}$. The experimental method and procedure used to evaluate material parameters is obviously of high importance and affects the results. The various methods used to evaluate the results of the same mechanical property seem to give widely spread data values, indicating difficulties and 
uncertainties in comparing values from different methods. Standardized test methods for evaluating the mechanical properties of snow make it easier to compare snow used in different investigations.

The residual strength, $E_{\text {res }}$, is linearly increasing with a strain rate that increases up to its critical value, or $0.003 \mathrm{~s}^{-1}$ for new machine-made snow. The residual strength, $E_{\text {res }}$, is lower than the values achieved by Vikström and Bernspång (2002) on machine-made snow at the same test temperature and is evaluated in the same way, that is, from compressive test curves. These results varied between 9 and $164 \mathrm{MPa}$. The increase in stress after the peak point is reach can be explained by the increase in the cross-sectional area of the specimen as the deformation proceeds. Another explanation is sintering or rearrangement of grains to form a more compact and stable structure. Eventually, compression converts the snow specimen into ice.

\section{Conclusion}

The major findings in this study are as follows:

- Unconfined strength tests on machine-made snow of different structures show that structure influences mechanical properties;

- Old and coarse-grained machine-made snow is more brittle than new and fine-grained machine-made snow;

- During uniaxial compression, a critical deformation rate exists at which the behavior changes from plasticity and strain hardening to brittleness or failure;

- Density is weakly correlated with compressive strength and Young's modulus, which may depend on the internal structure and high density of the machinemade snow; and

- In general, the uniaxial strength of machine-made snow is similar to natural snow of equal density.

\section{Appendix. Number of Test Samples for the Two Different Types of Machine-Made Snow}

\begin{tabular}{lcc}
\hline $\begin{array}{l}\text { Deformation rate } \\
(\mathrm{mm} / \mathrm{min})\end{array}$ & $\begin{array}{c}\text { Old snownumber } \\
\text { of samples }\end{array}$ & $\begin{array}{c}\text { New snownumber } \\
\text { of samples }\end{array}$ \\
\hline 0.5 & 3 & \\
1.5 & 5 & \\
3 & 3 & 3 \\
5 & 5 & 3 \\
7.5 & 3 & 3 \\
10 & 3 & 3 \\
12.5 & 3 & 3 \\
15 & 3 & 3 \\
17.5 & 3 & 5 \\
20 & 3 & 3 \\
25 & 3 & 3 \\
30 & 3 & 3 \\
35 & 3 & 3 \\
40 & 3 & \\
\hline
\end{tabular}




\section{Acknowledgments}

The authors want to thank Ulf Stenman and Mats Pettersson, Luleå University of Technology (LTU), for support with the strength tests and ICEHOTEL for its support and for providing the material studied. Part of the tests was funded by the EU regional fund through the project SNOW AND ICE.

\section{References}

Bader, H. (1962). The physics and mechanics of snow as a material, US Army Cold Regions Research and Engineering Laboratory, Arlington, VA.

Chen, J., and Kevorkian, V. (1971). "Heat and mass transfer in making artificial snow." Ind. Eng. Chem. Process Des. Dev., 10(1), 75-78.

Gold, L. W. (1956). "The strength of snow in compression." J. Glaciol., 2(20), 719-725.

ICEHOTEL. (2011). Information sheet: Presskit ICEHOTEL 2011/2012, Jukkasjärvi, Sweden.

Kinosita, S. (1958). "The relation between the deformation velocity of snow and two types of its deformation II (plastic and destructive)." Phys. Sci. Ser. A, 17, 11-30 (in Japanese).

Kinosita, S. (1967). "Compression of snow at constant speed." Phys. Snow Ice Proc., 1(2), 911-927.

Lintzén, N., and Edeskär, T. (2012). Study on basic material properties of machine-made snow, NGM 2012 Proc., Vol. 1, 371-379.

Mellor, M. (1974). A review of basic snow mechanics, U.S. Army Cold Regions Research and Engineering Laboratory.

Shapiro, L. H., Johnson, J. B., Sturm, M., and Blaisdell, G. L. (1997). "Snow mechanics review of the state of knowledge and application." CRREL Rep. 97-3, U.S. Army Corps of Engineers, Cold Regions Research and Engineering Laboratory, Hannover.

Vikström, L., and Bernspång, L. (2002). "Strength and deformation behaviour of snow and snow structures." Research Rep. 2002:13, Field and Laboratory Measurements at Icehotel, Jukkasjärvi Winter 2000-2001, Luleå Univ. of Technology, Luleå, Sweden.

Wakahama, G. (1968). "The metamorphism of wet snow." Int. Assoc. Sci. Hydrol., 79, 370-379.

Yong, R. N., and Fukue, M. (1977). "Performance of snow in confined compression." J. Terramech., 14(2), 59-82. 